\title{
Establishing monoxenic culture of arbuscular mycorrhizal fungus Glomus intraradices through root organ culture
}

\author{
M. Srinivasan*, K. Kumar, K. Kumutha and P. Marimuthu
}

Department of Agricultural Microbiology, Tamil Nadu Agricultural University, Coimbatore-641003 (Tamil Nadu), INDIA

*Corresponding author. E-mail: srinimicrotech@gmail.com

Received: April 9, 2014; Revised received: May 5, 2014; Accepted: June 10, 2014

\begin{abstract}
Arbuscular mycorrhizal fungi are soil fungi distributed worldwide, forming symbiosis with most of the vascular plants for their growth and survival, which is used for sustainable agriculture and ecosystem management. This study investigated the establishment of monoxenic cultures of Glomus intraradices in association with transformed carrot hairy root. The G.intraradices spores were isolated from sugarcane rhizosphere by wet sieving and decanting technique and propagated in open pot culture. Transformation in to carrot hairy root was done using Agrobacterium rhizogenes. Surface sterilization of G.intraradices spores co-cultured with transformed carrot hairy root in Modified Strulla and Romand (MSR) medium was found the host root growth as well as for germination AM spores. After three months of incubation in dark condition, significant production of extensive hyphal growth on MSR medium and an average of 8500-9000 spores per petri dish was observed. The in vitro inoculum exhibited higher potential of root colonization due to numerous intraradices mycelium with extensive spore load. The produced monoxenic inoculum can be used in place of traditional system where it has a advantage of producing contaminant free propagulas. Thus the monoxenic culture system, a powerful tool, of AM sporulation, can be used for the mass production of monoxenic inoculum of AM fungi besides studying its biology.
\end{abstract}

Keywords: Carrot hairy root induction, Glomus intraradices, Monoxenic inoculum, MSR medium, Sugarcane rhizosphere

\section{INTRODUCTION}

Continued increase in global population, with the limitations in the world's supply of natural resources, extensive use of chemical fertilizers and degeneration of the environment is a major challenge to the agricultural production today. Contrary to the chemical fertilizers, organic manures and bioinoculants are less expensive and achieving high productivity without harming the environment. In order to implement such a plan, the judicious use of nature's own biofertilizers such as arbuscular mycorrhizal fungi (AMF) (Frank, 1885) are Obligate symbionts behavior belonging to the phylum Glomeromycota (Schuessler et al., 2001) that cannot complete their life cycle without establishing a functional symbiosis with host plant. AMF enhances the nutrient availability especially phosphorus, augment water uptake and induces resistant against diseases and boost the crop yield (Lekberg and Koids, 2005). Conventional methods available for large scale production of AM fungi are pot cultivation with sterilized soil, aeroponics, hydroponics and green house based in vivo methods (Ijdo et al., 2011). However these methods have limitation in high quality inoculum production. Production of monoxenic AM culture under in vitro conditions is one of the most promising ways to obtain high number of spore propagules in a shortest time with contamination free inoculum (Binondo et al., 2012). Mosse (1962) first reported, the in vitro association of an Endogone species with plant. In the mid-1970s, Mosse and Hepper (1975) successfully established a culture of an AM fungus associated with excised roots of tomato (Lycopersicum esculentum Mill) and red clover (T. pratense L.) in gelled medium. After this primlinary work, ten years later the first observation of in vitro $\mathrm{AM}$ inoculum production using carrot hairy root was developed by Becard and Fortin in 1988. Similarly Chabot et al. (1992) developed monoxenic culture of AM using a mono-compartmental method. Using another approach Declerck et al., 1996, established in vitro AM inoculum by dual culture system having sterilized mycorrhizal root segments and Agrobacterium transformed carrot root. Fortin et al. (2002) used split-plate method of monoxenic culture, separating a proximal compartment containing the carrot root and AM fungus from a distal compartment to develop high density AM spore inoculum. Many different strains of AM fungi have been developed in monoxenic culture system. However, (Ijdo et al., 2011) reported that only Glomus intraradices species complex are fast colonizers that are able to multiply around ten thousand in vitro propagules in 5-7 months of incubation. However, all the above reported studies have taken a long period (around 7 monthes) to produce monoxenic AM spores using different explants. This sporulation time when 
compare to conventional methods is much longer and difficulty to commercialization. In order to produce high quality inoculum with higher number of spores in a relatively shorter period of time it is important to develop suitable method for inoculum mass production. Studies related to this area are less hence our present study aims to mass produce high potential monoxenic $G$. intraradices inoculum with help of transformed carrot hairy root in shorter time span.

\section{MATERIALS AND METHODS}

Fungal inoculum propagation: $G$. intraradices fungi used for this experiment was isolated from the rhizosphere of sugarcane and multiplied in pot culture of maize (Zea mays L. var-NK6240). The soil-sand $\operatorname{mix}(2: 1 \mathrm{w} / \mathrm{w})$ substrates were sterilized in an autoclave at $15 \mathrm{lb}$ for half an hour to kill the indigenones AMF propagules and to avoid cross contamination. After 60 of days incubation the soil samples were collected from pot, spores were isolated by wet-sieving and decanting technique (Daniels and Skipper, 1982). The mycorrhizal root were removed from pot culture, estimation of AM colonization was done by root clearing and staining technique (Phillips and Hayman, 1970)

Sterilization of spores: The $G$. intraradices spores were surface sterilized according to Becard and Piche (1992) by showing then for $10 \mathrm{~min}$ in a $2 \% \mathrm{w} / \mathrm{v}$ Chloramine-T with Tween $20(0.1 \% \mathrm{v} / \mathrm{v})$ which then followed by $30 \mathrm{~min}$ in antibiotic solution containg (Streptomycin 200 mg/lit, Ampicillin 200 mg/lit. Then spores were rinsed for several times with sterile distilled water and store at $4^{0} \mathrm{C}$.

Carrot hairy root culture: Freshly harvested carrots were surface sterilized using $0.1 \% \mathrm{HgCl}_{2}$ for $10 \mathrm{~min}$ with continuous stirring. They were further rinsed three times (each for $5 \mathrm{~min}$ ) in sterile distilled water and then dipped in $70 \%$ ethanol for $30 \mathrm{sec}$ and superficially flamed and peeled out. Each carrot was sliced into $0.5 \mathrm{~cm}$ thick discs and were placed on $0.5 \%$ MS (Murashige and Skoog1962) plates with the basal sides facing upwards. A loopful of 48 hours old A. rhizogenes (MTCC-532) strain was pricked manually for wounding on carrot surface and incubated at $28^{\circ} \mathrm{C}$ in dark for 2-3 weeks.

Monoxenic culture of $\mathrm{AM}$ inoculum production by root organ culture (ROC): The surface sterilized $G$. intraradices spores, and Ri-t-DNA transformed carrot hairy root were associated routinely in Modified Strulla and Romand (MSR) medium (Strulla and Romand 1986). The MSR mediun composed of (g/lit) $\mathrm{MgSO}_{4} 7 \mathrm{H}_{2} \mathrm{O}-73.9, \mathrm{KNO}_{3}-7.6, \mathrm{KCl}-6.5, \mathrm{KH}_{2} \mathrm{PO}_{4}{ }^{-}$ $0.41 \mathrm{Ca}\left(\mathrm{NO}_{3}\right)_{2} .4 \quad \mathrm{H}_{2} \mathrm{O}-35.9$, NaFeEDTA-0.16, microelements- $\mathrm{MnSO}_{4} .4 \mathrm{H}_{2} \mathrm{O}-1.225 \mathrm{CuSO}_{4} .5 \mathrm{H}_{2} 0-1.1$, $\mathrm{ZnSO}_{4} .7 \mathrm{H} 2 \mathrm{O}-0.14, \quad \mathrm{H}_{3} \mathrm{BO}_{3}-0.925, \quad \mathrm{Na}_{2} \mathrm{M}_{\mathrm{O}} \mathrm{O}_{4} \cdot-2 \mathrm{H}_{2} \mathrm{O}-$ $0.12 \quad\left(\mathrm{NH}_{4}\right) 6 \quad \mathrm{Mo}_{24} \cdot 4 \mathrm{H}_{2} \mathrm{O}-1.7$, Vitamins-Calcium panthotenate-0.09, Biotin-0.0001, Nicotinic acid-0.1, Pyridoxine-0.09, Thiamine- 0.1 and Cyanocobalamine0.04 Sucrose- 10 . The $\mathrm{pH}$ was adjusted to 5.5 before

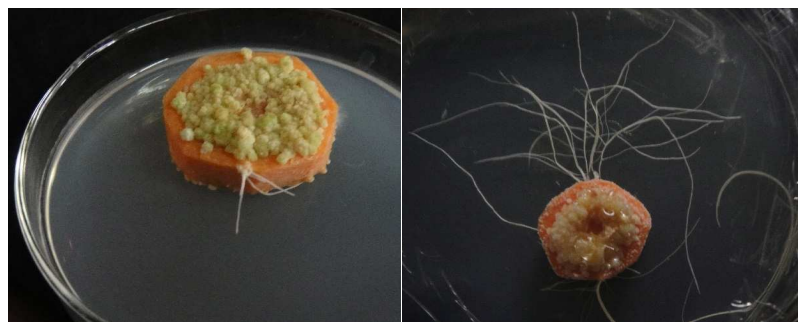

Figs.1\& 2. Hairy root induction from carrot after 1-2 week incubation on the MS medium.

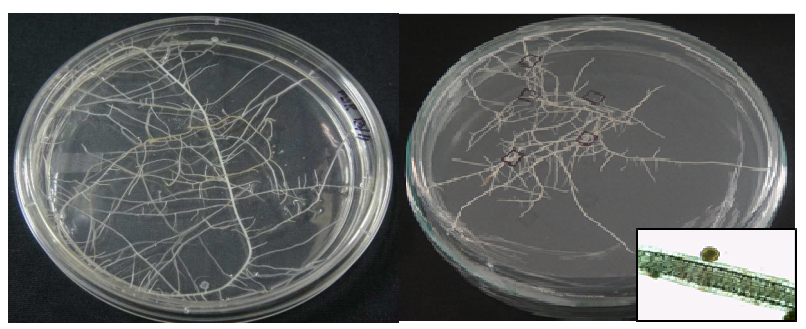

Fig. 3. Mass multiplication of Fig. 4. Co -Cultivation transformed hairy root on the through Root organ culture.

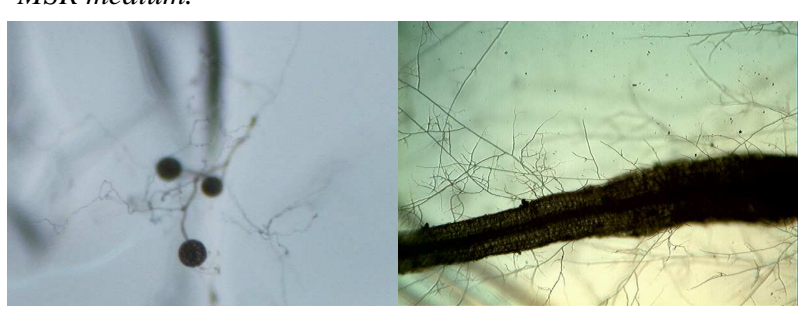

Fig.5. In vitro G. intraradi- Fig.6. Extensive hyphal ces spore germination and network growth. germ tube growth..

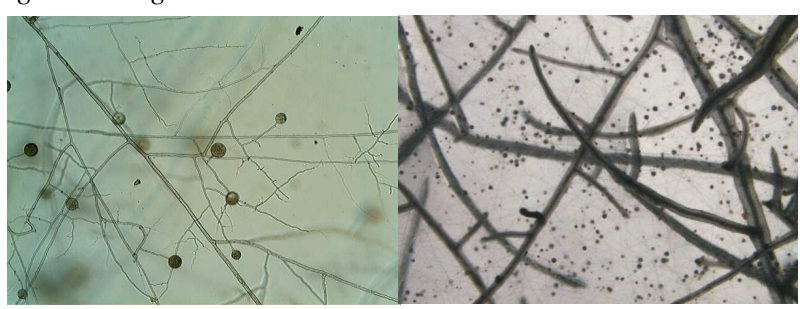

Fig.7. Formation of new G. Fig. 8. In vitro mass producintraradices spores from tion $G$. intraradices spores on germ tube. the MSR medium.
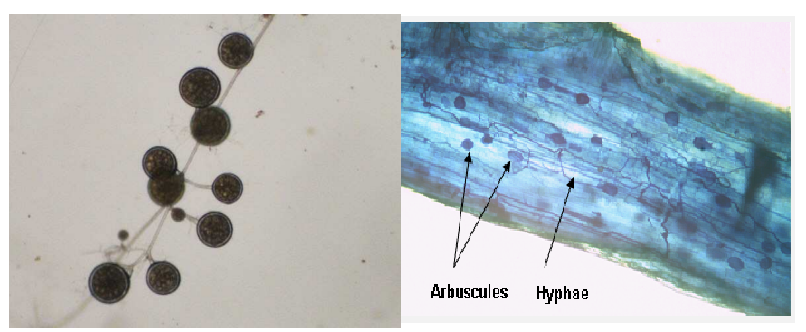

Fig.9. Cluster of mature in Fig.10. Presence of internal vitro G. intraradices hyphae and vesicles with in spores. mycorrizal infected carrot

adding gallon gum (3g/lit) after that the medium was sterilized @ $121^{\circ} \mathrm{C}$ for 15 mins. 10-15 spores of AM fungi were placed in different location near the emerging growth tip of pre grown carrot hairy root. Then plates were incubated in inverted position at $27{ }^{\circ} \mathrm{C}$ in the dark condition. 


\section{RESULTS}

Assessment of colonization potential of G. intraradices in pot culture: The root colonization potential of isolated $G$. intraradices AM fungus under green house condition was 45 percent and the maximum spore count $(140 / 100 \mathrm{~g}$ of soil $)$ was observed in sand mixture substrate after 60 days of inoculation. Plants subsequently grown without AMF had no sign of AM colonization. The results clearly indicated that the isolated $G$. intraradices spore is alive and viable with ability to colonize roots and multiply quickly at sixty days of inoculation.

Agrobacterium mediated- transformation: After 10 to 15 days of inoculation with Agrobacterium rhizogenes, callus induction was observed on the surface of carrot discs, followed by appearance of the transformed roots on the side wall of discs (Fig. 1). Hairy root initiation continued to occur upto 2-3 weeks (Fig. 2). A typical hairy root growth was observed the appearance of numerous lateral roots (Fig. 3) and its characteristic exhibiting the negative geotrophic growth habit. These transformed hairy roots were subsequently subcultured in fresh MS medium containing antibiotic solution, cefotaxime at $250 \mathrm{mg} / \mathrm{l}$ (HiMedia,Mumbai, India) to make it free from A. rhizogenes. The bacterial free hairy roots (around 6 $\mathrm{cm}$ long) were cut, transferred to a MSR medium and incubated for 5 days at $27{ }^{\circ} \mathrm{C}$ in the dark condition.

In vitro propagation $G$. intraradices: After seven days of co-cultivation, (Fig.4) the spore germination and hyphal growth was observed from surface sterilized $G$. intraradices spores (Fig. 5). with simultaneous growth of germ tube towards hairy root . After the initial contact between the germ tube and the root, the intercellular colonization took place on the $12^{\text {th }}$ day . During 18-20 days of incubation germ tube produced, multiply laterial branches on the root and media surface by extensive hyphal proliferation (Fig.6). After that, rapid enlargement of mycelium in the form of clusters and the formatiom if new spores (Fig.7) was observed within 30 days. The rate of spore formation was slow during next 30 Days which was followed by a rapid increase in spore number on $70^{\text {th }}$ days of incubation was observed. An average of 85009000 spores per petri dish was produced after 3 months of incubation (Figs. 8,9)

Three month old roots were harvested from prtidish, in vitro AM colonization was observed by root clearing and staining technique, the stained roots showed numerous internal hyphae, arbuscules and vesicles. The percentage of mycorrhizal colonization around $75-80 \%$ was recorded (Fig. 10)

\section{DISCUSSION}

Carrot is one of the most suitable and well known model plant species for hairy root production (Bidondo et al., 2012).In this present study, it was observed that inoculation of carrot discs with 48 hours old A. rhizogenes (MTCC-532) culture and incubated in darkness at $27^{\circ} \mathrm{C}$ provided a suitable condition for bacterial strains to insert their copies of Ri t-DNA. These findings were pointed out by Mugnier and Mosse, (1987) who observed that transformation efficiency is highly dependent on the bacterial strain used, which is related to the type of vir plasmid, binary plasmid or bacterial chromosomal background as a factor influencing hairy root initiation. The co-cultivation of $G$. intraradices spores with carrot hairy root was used in present study, because of their comfort of propagation and better adaption in culture than normal root. This result is supported by Douds (2002) and Gadkar et al. (2006), where transformed Daucus carota DC1 and DC2 hairy roots respectively have been successfully used to initiate monoxenic culture of AM fungi through root organ culture. In our study 3-7 days Co- Cultivation with transformed carrot root and $G$. intraradices spores, the hyphal growth was moves towards host root. Desouza and Berbara, 1999 observed that $80 \%$ of spore germination and hyphal growth, on the $14^{\text {th }}$ day of incubation. Hyphal growth lengths of over $10 \mathrm{~mm}$ from germination spores have been reported under the best experimental conditions (Douds and schenck,1991) After that germ tube branched and auxiliary cells grew in all directions followed by hyphae proliferation numerously near the root and density of hyphae on the surface of the medium. The same result was noted by Costa et al. (2013) who observed that in in vitro culture of Gigaspora decipiens and Clomus clarum produced typical structures like branched asorbing structure (BAS) after spores germination. Pratap chandran and potty (2010) also reported that in vitro co-culture of AM fungi C. microcarpum with Vigna vexilate hairy root on the 12-20 days of incubation $60 \%$ of media surface was covered with heavy mycelial network growth and fan-like structures were observed. After 30 days of incubation, it was observed that in this study heavy sporulation took place with extensive hyphal network. We observed numerous vegetative spores of $G$. intraradices were produced in the medium after two months and spores matured to light brown colour to a dark brown colour (Fig. 9). In our investigation, the rate of sporulation was higher after 70 days incubation. The reason might be due to the decrease of sucrose and other mineral component level in the medium. Similar trend was observed by James et al. (2013) who showed that the rate of sporulation depended on the sucrose concentration of the media. Medium supplement with sucrose had less sporulation than the medium without sucrose. This result was also supported by the study of Diop (1994) and Clark (1997) on Water agar medium without supplement mineral also showing support to sporulation of AM spores. In the present study MSR medium was most appropriate medium, through which approximately 8500 to 9000 spores can be produced per plate after 3 months of root organ culture. Ijdo et al. (2011) also reported that M medium (Becard and Fortin 1988) and MSR medium (Strullu and Romand 1986) are 
frequently used for culture AM fungi on ROC. Declarck et al. (1996) developed MSR medium to optimize the growth of intracellular mycelium and expensive sporulation of the fugues under in vitro condition. In event of sporulation Declerck et al. (2001) found same trends when carrot was used as host plant to produce 8,400 Glomus intraradices spores per petri plate after 12 weeks of incubation.

\section{Conclusion}

The root organ cultural method produced mycorrhizal root segments holding $G$. intraradices spore with Agrobacterium that transformed carrot hairy root as host partner on MSR medium, establishing mass production of pathogen free $G$. intraradices AM inoculum. This ROC method providing extensive monoexnic spore production in a small space and over short period of time. This type of AM inoculum production would significantly increase the number of spore loads, to be inoculated in field, greatly influencing the production of agricultural and horticulture crops.

\section{REFERENCES}

Becard, G. and Fortin, J. A. (1988). Early events of vesicular -arbuscular mycorrhiza formation on $\mathrm{Ri}$ T-DNA transformed roots. New Phytologist, 108: 211-218.

Becard, G. and Piche, Y. (1992). Establishment of vesiculr arbuscular mycorrhizal in root organ culture: review and proposed methodology. In Techniques for the study of mycorrhiza books, New York. pp. 89-108.

Bidondo, L. F., Pergola, M., Silvani, V., Colombo, R., Bompadre, J. and Godeas, A. (2012). Continuous and long-term monoxenic culture of the arbuscular mycorrhizal fungus Gigaspora decipiens in root organ culture. Fungal Biology, 116: 729-735.

Chabot, S., Becard, G. and Piche, Y. (1992). Life cycle of Glomus intraradix in root organ culture. Mycologia, 84: 315-321.

Clark, R. B. (1997). Arbuscular mycorrhizal adaptation, spore germination, root colonization, host plant growth and mineral acquisition at low pH. Plant Soil,192:15-22.

Costa, F. A., Haddad, L. S. M., Kasuya, M. C. M., Oton, W. C., Costa, M. D. and Borges, A. C. (2013). In vitro culture of Gigaspora decipiens and Glomus clarum in transformed roots of carrot: the influence of temperature and $\mathrm{Ph}$. Acta Scientiarum, 35:315-323.

Daniels, B. A. and Skipper, H. A. (1982). Methods for the recovery and quantitative estimation of propagules from soil. Methods and Principles of Mycorrhizal Research. American Phytopathological Society, pp. 29-35.

Declerck, S. D., Cranenbrouk, S. and Leboulenge, E. (2001). Modeling the sporulation dynamics of arbuscular mycorrhizal fungus in monoxenic culture. $M y$ corrhiza, 11:225-230.

Declerck, S., Strullu, D. G. and Plenchette, C. (1996). In vitro mass production of the arbuscular mycorrhizal fungus, Glomus versiforme, associated with Ri T-DNA transformed carrot roots. Mycological Research, 100 :1237-1242.

Desouza, F.A. and Berbara, R. L. (1999). Ontogeny of Glomus in Ri -T-DNA transformed root. Mycologia, 91: 343-345.
Diop, T.A., Plenchette, C. and Strullu, D. G. (1994a). Dual axenic culture of sheared-rood inocula of vesiculararbuscular mycorrhizal fungi associated with tomato roots. Mycorrhiza, 5: 17-22.

Douds, D. D. and Schenck, N.C. (1991). Germination and hyphal growth of VAM fungi during and after storage in soil at five matric potentials. Soil Biology and Biochemistry, 23: 177-183.

Douds, D.D. (2002). Increased spore production by Glomus intraradices in the split-plate monoxenic culture system by repeated harvest, gel replacement, and resupply of glucose to the mycorrhiza. Mycorrhiza, 12:163-167.

Fortin, J.A., Becard, G., Declerck, S., Dalpe, Y., StArnaud, M., Coughlan, A.P. and Piche, Y. (2002). Arbuscular mycorrhiza on root-organ cultures. Canadian Journal of Botany, 80: 1-20.

Frank, A.B. (1885). Uber die aut wurzal Symbiose benihende Eran ahrung genisser Baume durch unterridische Pilze. Berichte der Deutschen Botanischen Gesellschaft, 3: 128.

Gadkar, V., Driver, J.D. and Rillig, M.C. (2006). A novel in vitro cultivation system to produce and isolate soluble factors released from hyphae of arbuscular mycorrhizal fungi. Biotechnology Letters, 28:1071-1076.

IJdo, M., Cranenbrouck, S. and Declerck, S. (2011). Methods for large-scale production of AM fungi: past, present, and future. Mycorrhiza, 21: 1-16.

James, D.S., Rodrigues, K.M. and Rodrigues, B.F. (2013). Modified Strullu and Romand (MSR) Medium Devoid of Sucrose Promotes Higher Germination in in vitro Rhizophagus irregularis. Journal of Mycology and Plant Pathology, 43:240-242.

Lekberg, Y. and Koide, R.T. (2005). Is plant performance limited by abundance of arbuscular mycorrhizal fungi? A meta-analysis of studies published between 1988 and 200. New Phytologist, 168: 189-204.

Mosse, B. (1962). The establishment of vesicular arbuscular mycorrhiza under aseptic conditions. Journal of general microbiology, 27: 509-520.

Mosse, B. and Hepper, C.M. (1975). Vesicular-arbuscular infections in root organ cultures. Physiological and Molecular Plant Pathology, 15: 215-233.

Mugnier, J. and Mosse, B. (1987). Vesicular-arbuscular infections in Ri T-DNA transformed roots grown axenically. Phytopathology, 77: 10451050 .

Murashige, T. and Skoog, F. (1962). A revised medium for rapid growth and bioassays with tobacco tissue cultures. plant physiology, 15: 473-497.

Phillips, J. M. and Hayman, D. S. (1970). Improved procedures for clearing roots and staining parasitic and vesicular arbuscular mycorrhizal fungi for rapid assessment if infection. Transactions of the British Mycological Society, 55: 158-161.

Pratap Chandran, R. and Potty, V.P. (2010). In vitro co culture of VAM fungi clomus microcarpum in Ri T-DNA transformed hairy root of vigna vacillate. International Journal of Agriculture Environment and Biotechnology, 3: 333-338.

Schuessler, A., Schwarzott, D. and Walker, C. (2001). A new fungal phylum, the Glomeromycota: Phylogeny and evolution. Mycological Research, 105: 1413-1421.

Strullu, D. G. and Romand, C. (1986). Méthode d'obtention d' endomycorhizes a vesicules et arbuscules en condition axeniques. Comptes Rendus de Académie Sciences, 303:245-250. 